\title{
PRECOCIOUS SHEDDING OF THE ZONA PELLUCIDA IN RATS TREATED WITH PROGESTERONE
}

\author{
J. T. WU \\ Worcester Foundation for Experimental Biology, \\ Shrewsbury, Massachusetts 01545, U.S.A.
}

(Received 27th November 1972)

Rat blastocysts normally shed their zonae pellucidae on Day 5 (Day $1=$ spermatozoa in the vaginal smear) between 14.00 and 19.00 hours (Dickmann, 1967). In rats hypophysectomized on Day 1 and treated with various combinations of progesterone and oestrogen, many blastocysts as well as some morulae lose their zonae as early as 09.30 hours on Day 5 (Wu, Dickmann \& Johnson, 1971). The cause for such precocious shedding of the zona is not known. Since only a small amount of progesterone is secreted in the first 2 days of pregnancy (Hashimoto, Henricks, Anderson \& Melampy, 1968), it seemed possible that the precocious shedding of the zona observed in the previous experiments might result from the progesterone treatment on Days 1 and 2. The present study was designed to determine whether administration of progesterone to intact rats on Days 1 and 2 of pregnancy could cause precocious zona shedding and advance the time of implantation.

Holtzman rats were kept in air-conditioned quarters with lights on from 06.00 to 20.00 hours. Pro-oestrous females, weighing 200 to $250 \mathrm{~g}$, were caged with males overnight and the presence of a vaginal plug or spermatozoa in the vaginal smear the next morning was taken as evidence of mating (Day l of pregnancy). They were then assigned to the following treatments: (1) controls, $0 \cdot 1 \mathrm{ml}$ corn oil on Days 1 and 2; (2) $2 \mathrm{mg}$ progesterone on Day 1 only; and (3) $2 \mathrm{mg}$ progesterone daily on Days 1 and 2. Progesterone was administered subcutaneously in $0.1 \mathrm{ml}$ corn oil between 09.00 and 10.00 hours. The animals were killed at 09.00 to 11.00 hours on Day 5 and the uteri were trimmed and flushed with $0.9 \% \mathrm{NaCl}$ solution. The washings were examined under a dissecting microscope $(\times 40)$ and the recovered eggs were classified according to their stages of development, with or without zona pellucida (Wu et al., 1971).

To determine the time of implantation, two groups of rats were used: (1) controls, injected with $0 \cdot 1 \mathrm{ml}$ corn oil on Days 1 and $2 ;(2)$ progesterone-treated $-2 \mathrm{mg}$ progesterone daily on both Days 1 and 2. At various times on Day 5, the animals were injected intravenously with $0.4 \mathrm{ml} 0.9 \% \mathrm{NaCl}$ solution containing $1 \%$ Niagara Sky Blue (Hartman-Leddon Company, Philadelphia) and were killed 15 min later. The presence of discrete blue spots in the uterus would indicate an increased capillary permeability, which is one of the earliest signs of implantation (Psychoyos, 1960).

As shown in Table 1, in rats injected with $2 \mathrm{mg}$ progesterone on both Days 1 and 2 , an average of $5.7(60 \%)$ eggs were still inside their zonae but $3.9(40 \%)$ 


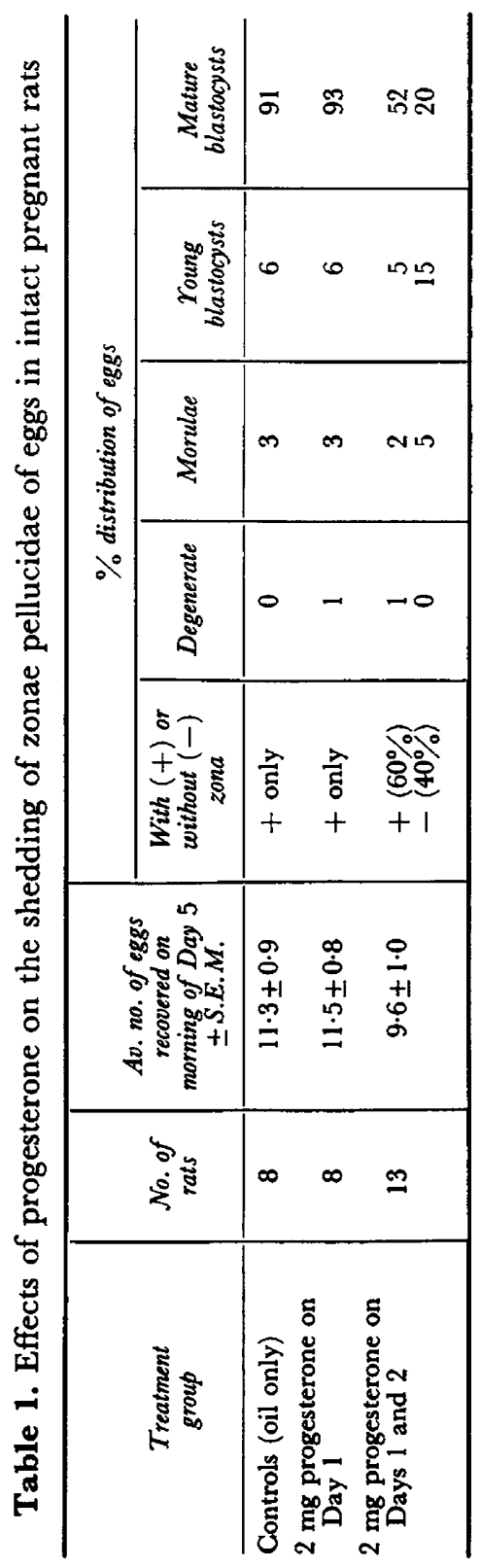




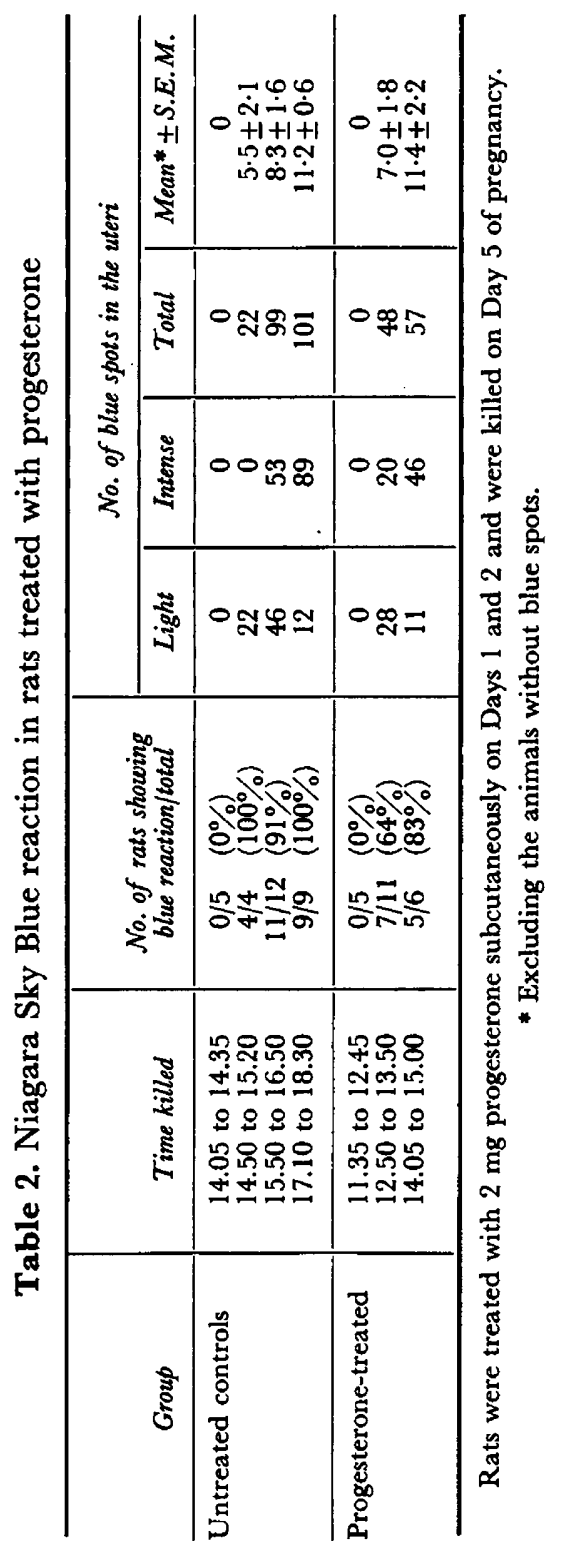


eggs were already free of zonae. Of the thirteen rats so treated, five had only zona-free eggs, another five had only zona-encased eggs while the remaining three had both kinds of eggs. No empty zonae were recovered, indicating that dissolution of zonae had occurred.

Niagara Sky Blue-staining spots first appeared in untreated controls at 14.50 hours, with an average of only 5.5 spots/rat (Table 2 ). Both the intensity of coloration and the number of blue spots/rat increased as time elapsed. By 18.30 hours, an average of 11.2 blue spots was observed, which was the same as the number of eggs recovered in the previous experiments (Table 1). This shows that all the eggs had already elicited a response from the uterus, though some interaction had proceeded farther than the others, as indicated by the different colour intensity.

In the progesterone-treated group, two discrete blue spots were seen in one animal at 12.50 hours, which was approximately $2 \mathrm{hr}$ earlier than the controls. All blastocysts had already initiated the blueing reaction in the progesteronetreated animals even before, or shortly after, the same reaction was begun in the control animals. All rats lacking blueing reaction in the uteri were found to contain only zona-encased blastocysts while the presence of blueing reaction was associated with the recovery of zona-free blastocysts from the uteri.

Both zona shedding and implantation can apparently be advanced by approximately $2 \mathrm{hr}$ by progesterone treatment.

Dickman (1969) has postulated that zona shedding of rat blastocysts can occur only after the maturation of the trophoblast, and that zona dissolution is caused by the action of a 'zona lysin' secreted from the blastocyst. McLaren $(1969,1970)$, however, suggested that the zona lysin is of uterine origin in the mouse. Recently, Brun \& Psychoyos (1972) raised the possibility of zona dissolution by a transient low $\mathrm{pH}$ value resulting from a high ATP concentration in the surrounding area. In the present study, as in the earlier one ( $\mathrm{Wu}$ et al., 1971), the zona was absent from a large proportion of morulae and young and mature blastocysts on the morning of Day 5 . Since the morula lacks the propulsive activity it needs to get out of the zona, its zona must have been dissolved or lysed without ever being shed as Dickmann (1972) suggested might occur in the intact rat. The results further suggest that the zonalytic factor may also originate from the morula cells and/or those of the uterus. The uterine origin of the zonalytic factor appears to be more likely because in pseudopregnant rats, the zonae of unfertilized eggs disappear in the afternoon of Day 5 (J. T. Wu, unpublished observation), at about the same time as those of blastocysts in pregnant rats (Dickmann, 1967). Since zona shedding is an oestrogen-sensitive process in ovariectomized rats and mice maintained on progesterone (Yasukawa \& Meyer, 1966; McLaren, 1970; Bergström, 1972; Dickmann, 1972), it appears that in the intact animal, the onset of zona shedding and dissolution is determined by the time of oestrogen surge.

Although the mechanism(s) by which the present progesterone treatment induced precocious shedding of the zona is not clear, two possibilities exist. First, the progesterone treatment may in some way advance the time of oestrogen surge. Second, progesterone administered on Days 1 and 2 may act in conjunction with the endogenous oestrogen on the uterus which has already 
been oestrogen-stimulated during oestrus. In either case, the uterus undergoes an earlier differentiation than usual so that the zonalytic factor is also secreted earlier. This explains the advance in the time of implantation in these animals. In the absence of oestrogen (as in the ovariectomized rat), progesterone produced the opposite effects (Dickmann, 1969, 1972). Even in intact rats which had insufficient amounts of endogenous oestrogen following treatment with medroxyprogesterone acetate (Barnes \& Meyer, 1964), zona shedding and dissolution were either delayed or blocked (Mantalenakis, 1971; Dickmann, 1972).

Precocious sensitization of the uterus has previously been produced in pseudopregnant rats by combined treatment with progesterone and oestrogen (Yoshinaga \& Greep, 1970). In one of their experimental groups (B-2) when rats were given $5 \mathrm{mg}$ progesterone daily (from the day of pro-oestrous to Day 8 of pseudopregnancy) and an injection of $0.2 \mu \mathrm{g}$ oestradiol on Day 4 , traumatization of the uterus on Day 5 failed to elicit a deciduoma. They attributed the decreased uterine sensitivity on Day 5 to the abnormally high level of oestrogen on Day 4 (i.e. the exogenous oestrogen in addition to the endogenous oestrogen surge). In the light of the present data, it also seems possible that several days of progesterone injections, coupled with the endogenous oestrogen, could alter the time of uterine sensitivity.

This work was supported by a grant (HD 03003) from the National Institute of Child Health and Human Development and by a grant from the Ford Foundation to Dr M. G. Chang, whose interest and guidance in this study were greatly appreciated.

\section{REFERENCES}

Barnes, L. E. \& MEYer, R. K. (1964) Delayed implantation in intact rats treated with medroxyprogesterone acetate. F. Reprod. Fert. 7, 139.

BERGSTRöm, S. (1972) Shedding of the zona pellucida in normal pregnancy and in various hormonal states in the mouse. A scanning electron microscope study. Z. Anat. EntwGesch. 136, 143.

Brun, J. L. \& Psychoyos, A. (1972) Dissolution of the rat zona pellucida by acidified media and blastocyst viability. F. Reprod. Fert. 30, 489.

Drckmann, Z. (1967) Shedding of the zona pellucida by the rat blastocyst. F. exp. Zool. 165, 127.

Dickmans, Z. (1969) Shedding of the zona pellucida. Adv. reprod. Physiol. 4, 187.

Dickmann, Z. (1972) Effects of progesterone, medroxyprogesterone acetate (Provera) and oestrone on shedding and dissolution of the zona pellucida in the rat. F. Endocr. 54, 39.

Hashimoto, I., Henricks, D. M., Anderson, L. L. \& Melampy, R. M. (1968) Progesterone and pregn-4-en-20 $\alpha$-ol-3-one in ovarian venous blood during various reproductive states in the rat. Endocrinology, 82, 333.

Mclaren, A. (1969) A note on the mouse zona pellucida. Adv. reprod. Physiol. 4, 207.

MaLaren, A. (1970) The fate of the zona pellucida in mice. F. Embryol. exp. Morph. 23, 1.

Mantalenakis, S. J. (1971) Induction of pseudopregnancy in rats treated with medroxyprogesterone. 7. Endocr. 50, 339.

Psychoyos, A. (1960) La réaction déciduale est précédée de modifications précoces de la perméabilité capillaire de l'utérus. C.r. Séanc. Soc. Biol. 154, 1384.

Wu, J. T., Dickmann, Z. \& Johnson, D. C. (1971) Effects of oestrogen and progesterone on the development, oviductal transport and uterine retention of eggs in hypophysectomized pregnant rats. 7. Endocr. 51, 569.

YasuKAwA, J. J. \& MEYER, R. K. (1966) Effect of progesterone and oestrone on the preimplantation and implantation stages of embryo development in the rat. 7. Reprod. Fert. 11, 245.

Yoshinaga, K. \& GReEp, R. O. (1970) Precocious sensitization of the uterus in pseudopregnant rats. Proc. Soc. exp. Biol. Med. 134, 725. 